\title{
Relationship between morphotypes of Atelognathus patagonicus (Anura, Neobatrachia) and environmental conditions: evidence and possible explanation
}

\author{
María Elena Cuello, Carmen A. Úbeda and María T. Bello \\ Departamento de Zoología, Centro Regional Universitario Bariloche, Universidad Nacional del Comahue, Quintral 1250, \\ R 8400 FRF San Carlos de Bariloche, Río Negro, Argentina. E-mail: mecuello@ bariloche.com.ar.
}

\begin{abstract}
Relationship between morphotypes of Atelognathus patagonicus (Anura, Neobatrachia) and environmental conditions: evidence and possible explanation. The frog Atelognathus patagonicus (Gallardo, 1962) is endemic to an endorheic pond system in basaltic basins, in Laguna Blanca National Park and its surroundings, in northwest Argentinean Patagonia. The species has two morphotypes, aquatic and littoral, which were studied in Laguna Batea, a semi permanent pond. Aquatic and terrestrial samples were taken over a period of 31 months, including periods of drought and periods of normal precipitation. Evidence was found of the reversible character of the two morphotypes. The changes in the phenotype were consistent with the water level and limnological conditions in the pond. We believe that the change and subsequent reversal of the somatic features in these frogs are an opportunistic alternative showing remarkable plasticity of the species, which can thus inhabit both permanent and temporary ponds. Therefore, the two morphotypes, aquatic and littoral, cannot be considered as "fixed forms" within a given population, as other authors have speculated, and do not correspond to ontogenetic states.
\end{abstract}

Keywords: Anura, Neobatrachia, Atelognathus patagonicus, morphotypes, phenotypic plasticity, reversible changes, Patagonia, Argentina.

\section{Introduction}

Changes in the behaviour, morphology and physiology of individuals that are induced by different environments are termed phenotypic

Received 22 January 2008.

Accepted 15 May 2008.

Distributed September 2008. plasticity (Price et al. 2003). Phenotypic plasticity reflects the organism's ability to change in response to changes in the habitat. For example, in response to pond drying, the larvae of some species of anurans exhibit accelerated developmental rates, at the expense of growth, to ensure metamorphosis to the terrestrial phase before all water is lost (e.g. Crump 1989, Newman 1989, Laurila and 
Kujasalo 1999). Reversible changes in morphology during the reproductive aquatic phases of urodeles are well known, for example the development of crenulated crest and pronounced tail fins in males of Triturus spp. (Halliday 1977), and large increase in body mass, head width, and tail height in Hynobius nigrescens males (Hasumi and Iwasawa 1990). Halliday (1977) and Hasumi and Iwasawa (1990) posit that when urodeles undergo an increase in surface area, their ability to absorb oxygen from the water also increases, therefore they probably remain underwater for longer periods of time, thus increasing their chances of successful breeding.

Reversible phenotypic changes are less well known in anurans. Adult males of the African hairy frog, Trichobatrachus robustus increase their oxygen uptake from water via transitory filaments of skin, which work as gills and enable them to carry out certain activities during the aquatic breeding phase (Noble 1925, Zippel 1997). Tadpoles of the gray treefrog, Hyla versicolor, respond to predators by means of reversible changes in their morphology (tail depth, body length) and behaviour (hiding behaviour, activity level) (Relyea 2003).

For Atelognathus patagonicus (Gallardo 1962), an endemic frog restricted to Laguna Blanca National Park and its surroundings, in NW Argentinean Patagonia, two "forms" have been described: "aquatic" and "littoral" (Cei and Roig 1968). The "aquatic form" lives in ponds, associated with underwater rocks, and has well-developed cutaneous folds, extensive interdigital membranes and an orange-yellow ventral surface. The "littoral form" lives in comparatively dry environments, under flat stones or in neighbouring hydrophilous meadows (mallines), $70-80 \mathrm{~m}$ away from the water's edge, and has small cutaneous folds, less-developed interdigital membranes and a greyish-white ventral surface (Figure 1).

The morphological differences, co-occurrence and different ecological niches of each "form" led Cei and Roig (1968) to propose that the two "forms" were in fact sympatric species. In two studies no relationship was found between the two "forms" and animal age or season (Cei and Roig 1968, Cei 1972). Later, Cei (1972) proposed that "aquatic" and "littoral forms" should be considered conspecific subspecies.

This study suggests that the two morphotypes described could be alternatively explained by a morphological transition from the aquatic morphotype to the littoral, and vice versa, if $A$. patagonicus were able to change in response to environmental fluctuations. To evaluate such hypothesis of the close link between the environment and the morphotypes, the present study is set out to test: $i$ ) whether morphological transition from one morphotype to the other is reversible and $i i)$ whether the environmental conditions are correlated with the proportion of morphotypes along a temporal ecological gradient.

\section{Material and Methods}

\section{Study area}

This study was conducted at Laguna Batea, a typical environment of the basaltic plateaus of the steppe in north-western Patagonia, where there is a population of $A$. patagonicus that has been studied. Laguna Batea (3902'02" S, $70^{\circ} 24^{\prime} 31^{\prime \prime} \mathrm{W}$; $1288 \mathrm{~m}$ elev.) is a pond located within Laguna Blanca National Park, Neuquén Province, Argentina. It belongs to an endorheic pond system formed by water filtering through basalt basins, occupying a depression partly surrounded by mechanically fragmented basalt and volcanic bombs. The pond has a maximum surface area of 2.5 ha and reaches a maximum depth of $2.7 \mathrm{~m}$. In contrast to most of the ponds in the system, which are permanent, Laguna Batea dries if precipitation events are scarce. It undergoes noticeable variations in its level during the year and between years. Precipitations are seasonal in the area; they are concentrated mainly in the austral autumnwinter period, while the dry season is the austral 

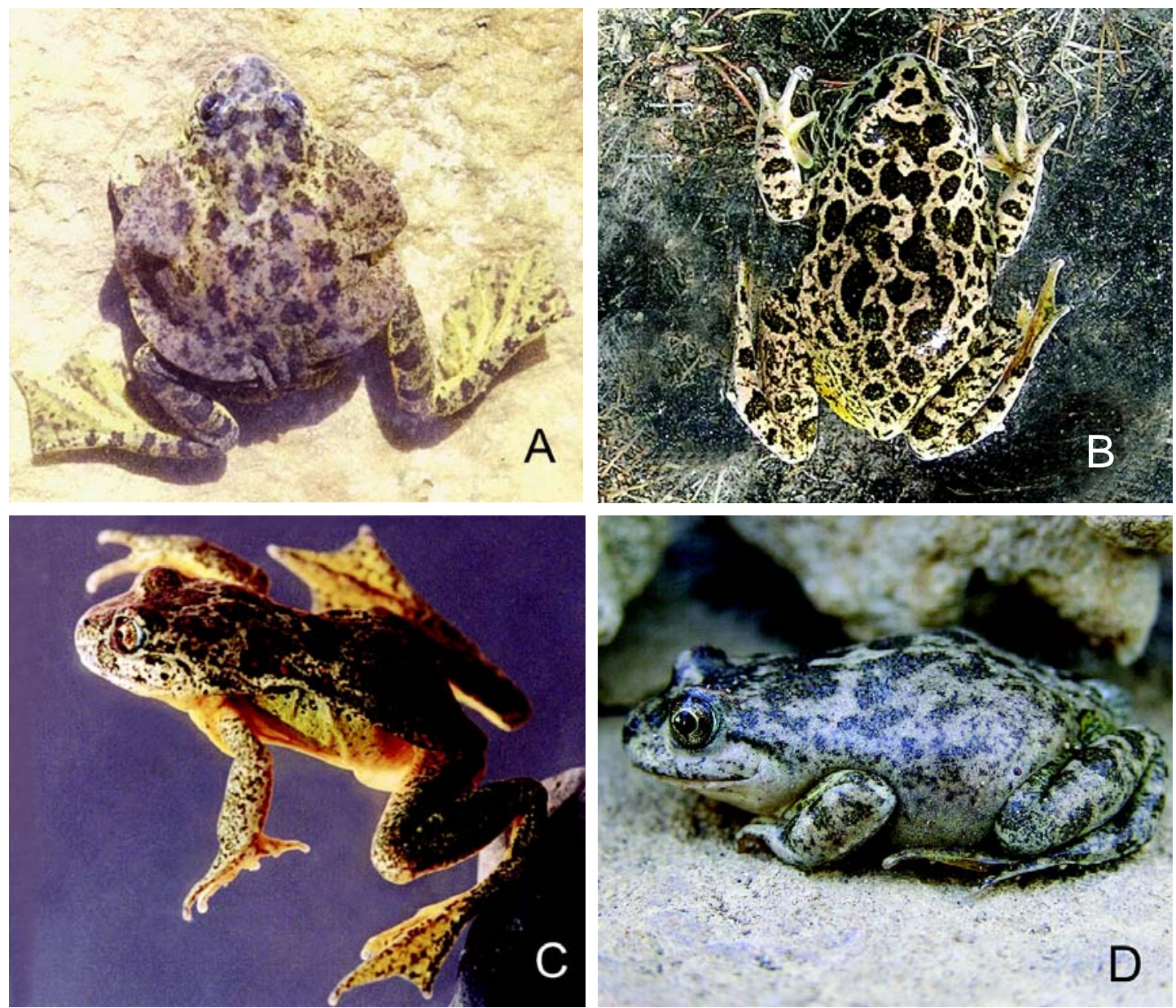

Figure 1 - Atelognathus patagonicus. (A,C) Dorsal and lateral view of aquatic morphotype. Photographs by C. A. Úbeda. (B,D) Dorsal and lateral view of littoral morphotype. (B) photograph by M.E. Cuello; (D) photograph by G. Ignazi.

summer (Figure 2). The pond is deepest in spring, as a result of the runoff from rainfall and snowmelt, and shallowest in late summer. During winters the pond surface freezes. About $75 \%$ of the shore has fine clay sediment and herbaceous hydrophilous vegetation made up of grasses and rushes. The rest of the shore has fine sediment with scattered volcanic rocks. The rooted macrophyte Myriophyllum quitense emerges from the pond, and, particularly when the volume of water decreases, covers the entire surface.

\section{Sampling design}

Samples were taken once a month from November 2003 to May 2006. At each visit, A. patagonicus population censuses were taken in both the aquatic and terrestrial environment. The pond was monitored by means of surface and depth records, water temperature and state of macrophytes. From November 2003 to June 2004, water temperature was recorded at midday on each visit. In September 2004, a data-logger (HOBO Water Temp Pro) was installed at a depth 


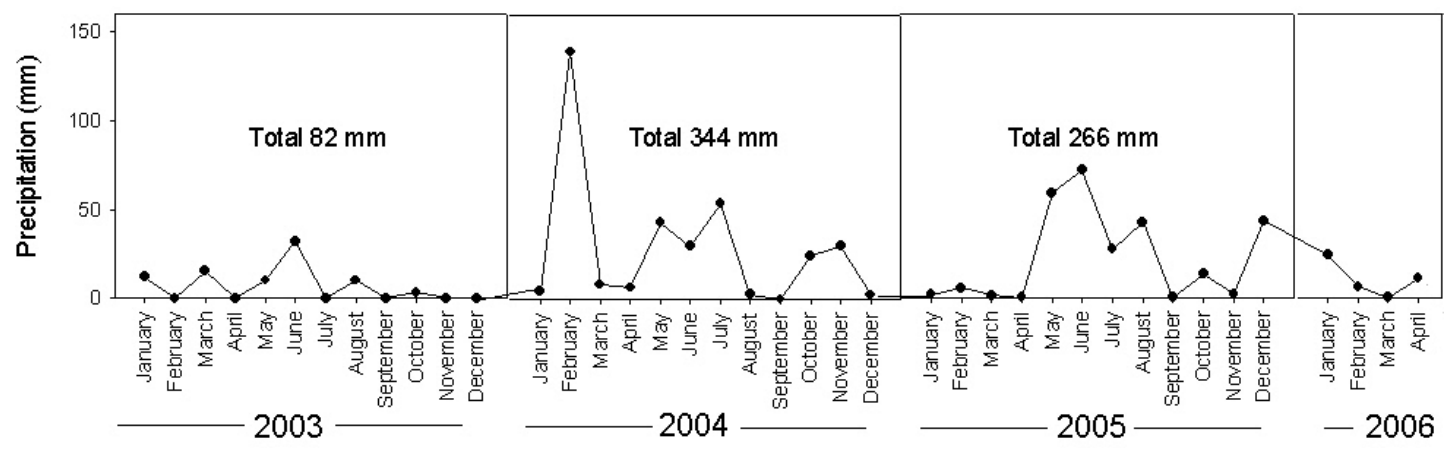

Figure 2 - Monthly precipitations during the period January 2003-April 2006. Annual totals are shown at the top. Source: Zapala Airport Meteorological Station, Neuquén Province, Argentina.

of $0.5-1 \mathrm{~m}$ to calculate mean monthly temperatures (from data recorded hourly).

For aquatic samples we used plastic funnel traps (11 cm diameter, $30 \mathrm{~cm}$ long) with a single funnel (Smith and Rettig 1996). Traps were placed at the bottom of the pond parallel to the shoreline from $0.2 \mathrm{~m}$ to $0.8 \mathrm{~m}$ depth at 5 $\mathrm{m}$ intervals and left undisturbed overnight. The pond was not sampled during February, March and April 2004 because the pond was muddy and prior experience has shown no capture success in these conditions. For land samples, we set up three parallel band transects along the coastline, $50 \mathrm{~m}$ long and $2 \mathrm{~m}$ wide. All the rocks within each transect were picked up and all specimens captured by hand. The rocks were replaced in their original position. When the pond was drying, we used different sampling approaches: $i$ ) in April 2004 all the pond was sampled by sweeping a drag net (ring wade type) for 3 hours, and ii) a $1.500 \mathrm{~m}^{2}$ rectangular area of the dry bed $(30 \mathrm{~m}$ perpendicular to the edge of the pond $x 50 \mathrm{~m}$ along the shoreline) was marked. Within the area, all the rocks were checked and then left in their original positions. For each specimen, the distance from the point where it was found to the shoreline at that time was recorded. At each sampling event, the specimens collected were placed in containers of pond water, counted, length (SVL) and morphotype recorded, and then released at the site they had been captured. For morphotype, the two "forms" by Cei and Roig (1968) were considered. We excluded from the analysis any individuals with other characteristics (presence of integumentary folds and interdigital membranes of medium development, and a uniform, pale yellowish grey ventral colouring), and the newly metamorphosed specimens $(\leq 24 \mathrm{~mm} \mathrm{SVL})$.

The proportion of each morphotype in each environment (water or land) was calculated every month to evaluate evolution of the population over time and have indirect evidence of the reversible character of the morphological transition between morphotypes. The Spearman rank test was used to examine the correlation between water depth and temperature and the proportion of the littoral morphotype in the samples. This analysis was performed during two periods of time: an atypical period of major drought (November 2003 - December 2004), and a period of normal precipitation (January 2005 - May 2006). The Bonferroni method $(P \leq 0.025)$ was applied to the correlations.

\section{Results}

\section{Pond conditions}

The year 2003 was particularly dry, with 82 $\mathrm{mm}$ total precipitation (Figure 2 ) and by the end 


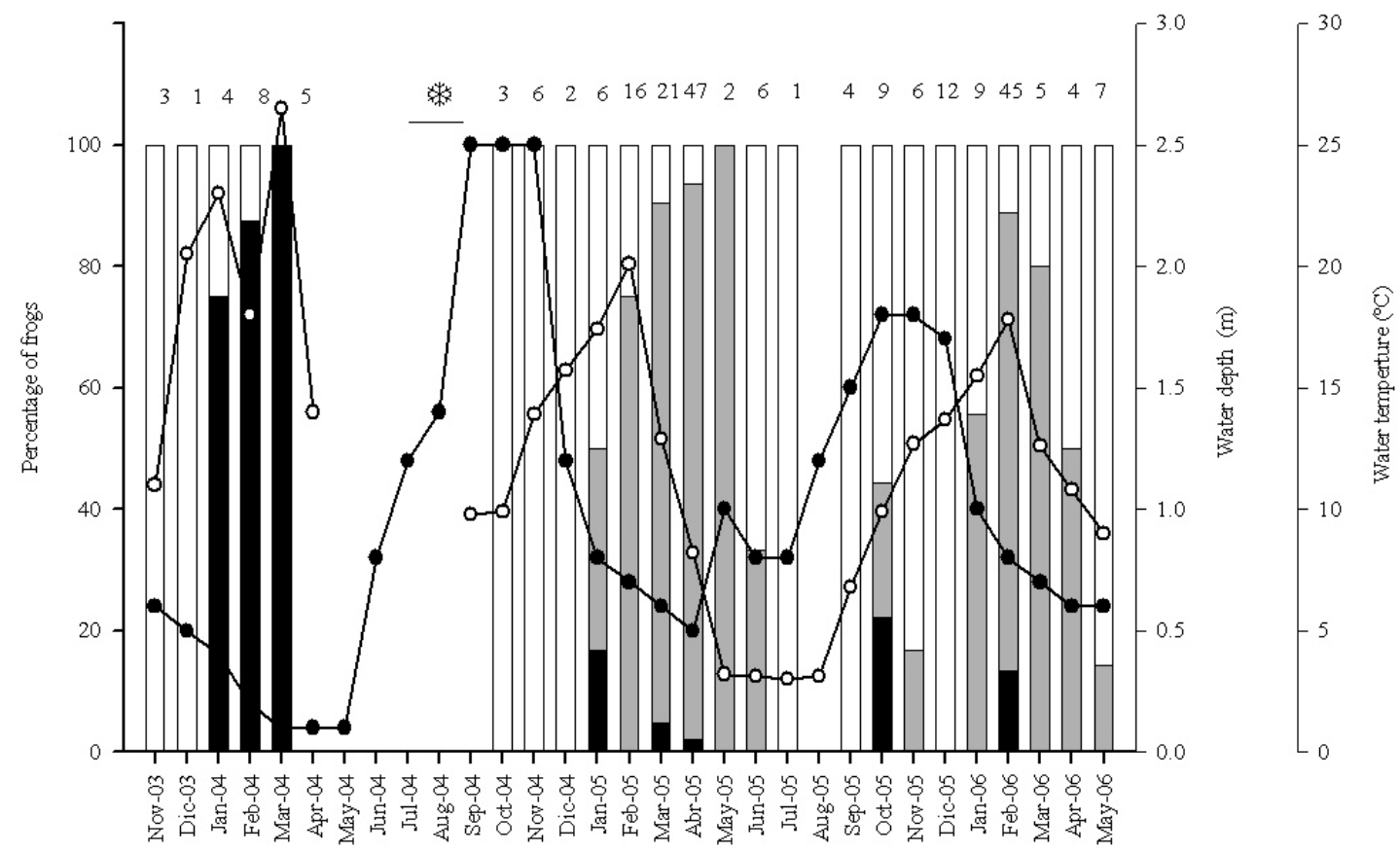

Figure 3 - Distribution of percentages of Atelognathus patagonicus specimens, water temperature and water depth in monthly samples (November 2003 to May 2006) from Laguna Batea. White bar = aquatic morphotype; black bar $=$ littoral morphotype, grey bar = others (set of frogs with intermediate characteristics between aquatic and littoral morphotypes); = area covered in snow; $\bullet=$ water depth; $\bigcirc=$ water temperature. Temperature November 2003-June 2004: recorded at midday; September 2004 to May 2006: monthly means.

of the year, the water level in Laguna Batea was low (Figure 3). In March-April 2004 (dry season) the water level was shallowest $(10 \mathrm{~cm})$, with only a muddy residue remaining. In JulyAugust 2004 (winter), the entire area was covered in snow. In September 2004 (runoff season), Laguna Batea recovered and attained its maximum depth $(2.50 \mathrm{~m})$ (Figure 3). During the 2003-2004 dry season, oxygen level was low $\left(3.1 \mathrm{mg} \mathrm{L}^{-1}\right)$ and water temperature increased $\left(>20^{\circ} \mathrm{C}\right.$ at midday, Figure 3 ); this was concomitant with the senescence and death of most of the macrophytes, an increase in plant detritus, and increasing smell of hydrogen sulphide.

During 2004 and 2005 annual precipitation was $344.6 \mathrm{~mm}$ and $266 \mathrm{~mm}$, respectively (Figure 2), and in both years, the volume of precipitation during the rainy and snowy seasons (May to July each year) was enough to feed the pond, whose minimum level was 50 and $60 \mathrm{~cm}$ during the 2005 and 2006 dry seasons respectively (Figure 3 ). In each dry season (January-April 2005 and 2006) water temperature (Figure 3 ) and turbidity increased and senescent and decomposing filamentous algae could be observed. The January 2005May 2006 period was comparatively less severe than November 2003-December 2004 period.

\section{Frogs}

From November 2003 to December 2004, a wide range of frog sizes was recorded, ranging from $24.3 \mathrm{~mm}$ SVL to $43.7 \mathrm{~mm} \mathrm{SVL}$. The latter is near the maximum size we found for the species. The sampling effort rendered 14 
Table 1 - Number of Atelognathus patagonicus specimens in the monthly samples (November 2003 to December 2004) from Laguna Batea, discriminated by morphotypes and capture site. Others = set of frogs with intermediate characteristics between aquatic and littoral morphotypes. Area covered in snow; - data not available.

\begin{tabular}{cccccccc}
\hline \multirow{2}{*}{ Date } & \multicolumn{3}{c}{ Aquatic habitat } & \multicolumn{3}{c}{ Terrestrial habitat } \\
\cline { 2 - 7 } 2003 & $\begin{array}{c}\text { Aquatic } \\
\text { morphotype }\end{array}$ & $\begin{array}{c}\text { Littoral } \\
\text { morphotype }\end{array}$ & Others & $\begin{array}{c}\text { Aquatic } \\
\text { morphotype }\end{array}$ & $\begin{array}{c}\text { Littoral } \\
\text { morphotype }\end{array}$ & Others \\
\hline \multirow{2}{*}{ Nov } & 2 & 0 & 0 & 1 & 0 & 0 \\
& Dec & 1 & 0 & 0 & 0 & 0 & 0 \\
& Jan & 0 & 0 & 0 & 1 & 3 & 0 \\
& Feb & 0 & 0 & 0 & 1 & 7 & 0 \\
& Mar & 0 & 0 & 0 & 0 & 5 & 0 \\
& Apr & 0 & 0 & 0 & 0 & 0 & 0 \\
& May & 0 & 0 & 0 & 0 & 0 & 0 \\
& June & 0 & 0 & 0 & 0 & 0 & 0 \\
& July & - & - & - & - & - & - \\
& Aug & - & - & - & - & - & - \\
& Sept & 0 & 0 & 0 & 0 & 0 & 0 \\
& Oct & 3 & 0 & 0 & 0 & 0 & 0 \\
& Nov & 6 & 0 & 0 & 0 & 0 & 0 \\
& Dec & 2 & 0 & 0 & 0 & 0 & 0 \\
\hline Total & $\mathbf{1 4}$ & $\mathbf{0}$ & $\mathbf{0}$ & $\mathbf{3}$ & $\mathbf{1 5}$ & $\mathbf{0}$ \\
\hline
\end{tabular}

specimens captured in water and 18 on land (Table 1). These samples represent captures in water in November and December 2003, and October to December 2004; and captures on land in November 2003 and January to March 2004. During this period, all the specimens captured in water were of the aquatic morphotype ( 30.4 to $43.7 \mathrm{~mm} \mathrm{SVL}$ ), while the specimens captured on land included both the aquatic morphotype (29.5 to $43 \mathrm{~mm} \mathrm{SVL}$ ) and the littoral morphotype (24.3 to $40.7 \mathrm{~mm} \mathrm{SVL}$ ).

Figure 3 shows that only specimens of the aquatic morphotype were captured in November and December 2003, whereas in January and February 2004, when the pond was smaller, 75 and $87.5 \%$ of the frogs, respectively, had the typical littoral morphotype $(100 \%$ of these specimens were found under volcanic rocks, whether on the transect or outside it, up to $12 \mathrm{~m}$ away from the shore). In March 2004, all specimens were of the littoral morphotype (found under rocks, 4 to $30 \mathrm{~m}$ away from the shoreline). No specimens were captured during the thorough sampling of the residual pond bed with a drag net.

The rocks under which the frogs were found during the dry season become submerged once again when the water level rises. From October to December 2004, frogs exhibiting the aquatic phenotype were found again (all within the pond boundaries). The abdominal colouring of $45.5 \%$ of these was a transition between the aquatic and littoral morphotypes: an entirely grey belly and orange-yellow colour at the base 
Table 2 - Number of Atelognathus patagonicus specimens in the monthly samples (January 2005 to May 2006) from Laguna Batea, discriminated by morphotypes and capture site. Others = set of frogs with intermediate characteristics between aquatic and littoral morphotypes.

\begin{tabular}{|c|c|c|c|c|c|c|c|}
\hline & & & uatic habitat & & & rrestrial habi & \\
\hline & & $\begin{array}{c}\text { Aquatic } \\
\text { morphotype }\end{array}$ & $\begin{array}{c}\text { Littoral } \\
\text { morphotype }\end{array}$ & Others & $\begin{array}{c}\text { Aquatic } \\
\text { morphotype }\end{array}$ & $\begin{array}{c}\text { Littoral } \\
\text { morphotype }\end{array}$ & Others \\
\hline 2005 & Jan & 1 & 0 & 1 & 2 & 1 & 1 \\
\hline & Feb & 4 & 0 & 0 & 0 & 0 & 12 \\
\hline & Mar & 0 & 0 & 3 & 2 & 1 & 15 \\
\hline & Apr & 3 & 1 & 43 & 0 & 0 & 0 \\
\hline & May & 0 & 0 & 0 & 0 & 0 & 2 \\
\hline & June & 4 & 0 & 2 & 0 & 0 & 0 \\
\hline & July & 1 & 0 & 0 & 0 & 0 & 0 \\
\hline & Aug & 0 & 0 & 0 & 0 & 0 & 0 \\
\hline & Sept & 4 & 0 & 0 & 0 & 0 & 0 \\
\hline & Oct & 5 & 2 & 2 & 0 & 0 & 0 \\
\hline & Nov & 5 & 0 & 0 & 0 & 0 & 1 \\
\hline & Dec & 9 & 0 & 0 & 3 & 0 & 0 \\
\hline 2006 & Jan & 4 & 0 & 5 & 0 & 0 & 0 \\
\hline & Feb & 4 & 2 & 20 & 1 & 4 & 14 \\
\hline & Mar & 1 & 0 & 3 & 0 & 0 & 1 \\
\hline & Apr & 2 & 0 & 1 & 0 & 0 & 1 \\
\hline & May & 6 & 0 & 1 & 0 & 0 & 0 \\
\hline Total & & 53 & 5 & 81 & 8 & 6 & 47 \\
\hline
\end{tabular}

of the limbs, with irregular boundaries between the two colours.

The correlation between the percentage of the littoral morphotype specimens and water depth was $r=-0.864(P=0.006)$. The correlation between the percentage of the littoral morphotype specimens and water temperature was $r_{\mathrm{s}}=0.736(P=0.037)$.

From January 2005 to May 2006 the $69.5 \%$ of the specimens were captured in the aquatic environment. Specimens were captured in the water in 15 of the 17 months in which samples were taken, while they were only captured on land in 9 of the 17 months, with peaks in summer (Table 2). The samples added up to 61 $(30.5 \%)$ specimens of the aquatic morphotype (24.1 to $46.5 \mathrm{~mm} \mathrm{SVL),} 11$ (5.5\%) specimens of the littoral morphotype ( 24.6 to $33 \mathrm{~mm} \mathrm{SVL}$ ) and $128(64 \%)$ specimens with intermediate characteristics (24.1 to $32 \mathrm{~mm} \mathrm{SVL}$ ) (Table 2).

Specimens with the littoral morphotype made up $3.6 \%$ of the specimens captured in the water and $9.8 \%$ of the specimens captured on land. Eighty seven percent of the specimens with the aquatic morphotype were captured in the water and those captured on land (13\%) were found near the water's edge (Table 2). Throughout this period, frogs of the aquatic 
morphotype were captured in 15 of the 17 monthly samples taken (Figure 3); on three occasions (July, September and December 2005) only frogs of the aquatic morphotype were captured. Practically one third $(29.5 \%)$ of the individuals of the aquatic morphotype presented an atypical ventral colouring (an entirely grey belly and orange-yellow colour at the base of the limbs) which had already been observed during October-December 2004. From January 2005 to May 2006 there was no correlation between the percentage of individuals of the littoral morphotype and pond depth $\left(r_{\mathrm{s}}=0.148 ; P=0.585\right)$ or water temperature ( $\left.r_{\mathrm{s}}=0.297 ; P=0.264\right)$.

In brief, while the pond contained water (November and December 2003) frogs of the aquatic morphotype were captured, both underwater and on the shore transects. As the water level descended (January-February 2004, summer), the frogs captured began to present the morphology and colouring typical of the littoral morphotype and were found in the terrestrial samples. No specimens of the aquatic morphotype were found during the period between the time the pond dried up completely (March 2004, late summer) and the time it filled again, in spring (September 2004). When the pond filled, the aquatic morphotype reappeared, made up of typical specimens plus a subset of frogs without the uniform orange-yellow ventral colouring. During the 2005 and 2006 dry seasons, when water level was lowest, the pond still contained a certain amount of water and retained its population of frogs.

\section{Discussion}

This study monitored the occurrence of two different morphotypes of the frog Atelognathus patagonicus. Our findings are consistent with the hypothesis that this species has at least two morphotypes and that these may be reversible in response to environmental conditions. Information on reversible changes in amphibians is scarce, although seasonal morphological changes related to breeding are known in some male urodeles and anurans. The study conducted in Laguna Batea produced the first records of the entire Atelognathus patagonicus population moving between water and land, with individuals changing back and forth from the aquatic morphotype to the littoral morphotype, according to the changes in water level and conditions of the habitat. The fact that there is a wide size range of frogs that make up both morphotypes allows us to infer that the acquisition of the characteristics of each morphotype does not depend on age-size of individuals, and supports the idea that these changes are linked to a set of environmental variables. In particular, during the driest season, there was a significant correlation between shallower water and the littoral morphotype. These results are a progress on the opinions of Cei and Roig (1968) and Cei (1972), who did not believe that seasonal or cyclical factors were related to the existence of the "forms" of A. patagonicus that they defined.

Reversible adjustments of morphology, physiology and behaviour to varying environmental conditions suppose a process of acclimatization which enables survival or improved performance of the population in a new environment. In our study, when the volume of water decreases during dry periods, the frogs that find temporary shelter and food under the rocks in the littoral area cannot reach any other aquatic environment due to the isolation of the pond where they live; according to our records, they were found as far as $30 \mathrm{~m}$ from the shoreline. The frogs withstand terrestrial environmental conditions by altering their phenotype and feeding behaviour (Cuello et al. 2006a).

When favourable conditions return as the water level rises, the frogs of the littoral morphotype have the possibility of returning to the aquatic environment. We posit that the aquatic and littoral morphotypes may be reversible and therefore cannot be considered fixed within a given population as Cei (1972) 
proposed. If so, when the frogs return to the water they can recover the typical characteristics of the aquatic morphotype, including extensive interdigital membranes and specialized integument, with richly vascularized folds which enable cutaneous gas exchange. In this case, the biological role of the character (sensu Larson and Losos 1996) makes sense as long as the individuals remain in the aquatic environment. The functionality and efficiency of this kind of respiratory surface is well known in Telmatobius culeus, the lake Titicaca frog which is very well adapted to living in the water (Hutchison et al. 1976). For A. patagonicus, the passive oscillation of the skin folds while swimming would contribute to ventilation, to the point that the frogs are able to survive in summer even in water with high content of decomposing organic matter. On land, the reduction of membranes may constitute a different strategy because it prevents loss of moisture.

The changes in ventral skin colouring in Atelognathus patagonicus can be associated to the type of prey they feed on. The aquatic morphotype feeds on amphipods of the genus Hyalella (Cuello et al. 2006a, b), which has a high content of carotenoid pigments, and produces the typical orange-yellow ventral colour in the frogs. In terrestrial habitats, the frogs feed on various aerial arthropods instead of amphipods (Cuello et al. 2006a), which appears to cause the greyish-white ventral colouring of the littoral morphotype. The fact that some individuals with well-developed folds and interdigital membranes present a ventral colouring with greyish-white and orange-yellow patches is consistent with the idea that there could be a gradual change in frog phenotype, associated to the habitat that provides different food.

The time required for a change to become apparent in the proportion of morphotypes is variable. The records were different in the two periods studied: i) synchronous, relatively fast change (January-March 2004), and ii) scattered, less conclusive change during the following period. The environmental conditions during the
2005-2006 period allowed the population to live in the water for a longer time, and no massive presence of littoral morphotype was observed. The process seems to be linked to the behaviour of environmental variables and therefore not to have a set annual pattern.

The remarkable plasticity of the species enables it to become acclimatized to different environments, and consequently able to live both in permanent and temporary ponds. Atelognathus patagonicus appears to be strongly linked to the water. The aquatic morphotype is the most common and lives mainly in permanent ponds (Fox et al. 2005). The frogs of the littoral morphotype were linked especially to terrestrial environments. Apparently, A. patagonicus is well adapted to living as an aquatic frog. Permanent ponds suit it because they reduce the risks of dehydration and possibly predation, and provide room to manoeuvre and a steady, plentiful food supply (M. E. Cuello, unpubl. data). In contrast, the littoral morphotype should be considered to be an opportunist alternative of the species, thus explaining its lower frequency in permanent ponds.

\section{Acknowledgements}

We would like to thank M. G. Perotti, N. Baccalá and G. Garibotti for suggestions on methodology; M. Calvo for her work as a field assistant; park rangers of Laguna Blanca National Park and technicians from Delegación Regional Patagonia of APN for supporting our field work; and two anonymous reviewers and the editors for their suggestions on the manuscript. This project was partly supported by research grants from Universidad Nacional del Comahue (B 101), Wildlife Society Conservation (Research Fellowship Program) and Rufford Small Grant (for nature conservation) in association with Whitley Laing Foundation. Capture of specimens was authorized by Administración de Parques Nacionales (Disp. DNCAP N55/04). 


\section{References}

Cei, J. M. 1972. Herpetología patagónica V. Las especies extra-cordilleranas alto patagónicas del género Telmatobius. Physis 31: 431-449.

Cei, J. M. and V. G. Roig. 1968. Telmatobiinos de las lagunas basálticas de Neuquén (Anura, Leptodactylidae). Physis 27: 265-284.

Cuello, M. E., M. T. Bello, M. Kun, and C. A. Úbeda. 2006a. Feeding habits and their implications for the conservation of the endangered semiaquatic frog Atelognathus patagonicus (Anura, Neobatrachia) in a northwestern Patagonian pond. Phyllomedusa 5: 67-76.

Cuello, M. E., C. A. Úbeda, M. T. Bello, and M. Kun. 2006b. Atelognathus patagonicus (NCN). Diet. Herpetological Review 37: 198-199.

Crump, M. L. 1989. Effect of habitat drying on developmental time and size at metamorphosis in Hyla pseudopuma. Copeia 1989: 794-797.

Fox, S. F., J. H. Yoshioka, M. E. Cuello, and C. Úbeda. 2005. Status, distribution, and ecology of an endangered semi-aquatic frog (Atelognathus patagonicus) of northwestern Patagonia, Argentina. Copeia 2005: 921-929.

Halliday, T. R. 1977. The courtship of European newts: an evolutionary perspective. Pp. 185-232 in D. H. Taylor and S. I. Guttman (eds.), The Reproductive Biology of Amphibians. New York. Plenum Press.

Hasumi, M. and H. Iwasawa. 1990. Seasonal changes in body shape and mass in the salamander, Hynobius nigrescens. Journal of Herpetology 24: 113-118.

Hutchison, V. H., H. B. Haines and G. A. Engbretson.
1976. Aquatic life at high altitude: respiratory adaptations in the Lake Titicaca frog, Telmatobius culeus. Respiration Physiology 27: 115-129.

Laurila, A. and J. Kujasalo. 1999. Habitat duration, predation risk and phenotypic plasticity in common frog (Rana temporaria) tadpoles. Journal of Animal Ecology 68: 1123-1132.

Larson, A. and J. B. Losos. 1996. Phylogenetic systematics of adaptation. Pp. 187-220 in M. R. Rose and G. V. Lauder (eds.), Adaptation. San Diego. Academic Press.

Newman, R. A. 1989. Developmental plasticity of Scaphiopus couchii tadpoles in an unpredictable environment. Ecology 70: 1775-1787.

Noble, G. K. 1925. The integumentary, pulmonary, and cardiac modifications correlated with increased cutaneous respiration in the Amphibia: a solution of the "hairy frog" problem. Journal of Morphology and Physiology 40: 341-416.

Price, T. D, A. Qvarnström and D. E. Irwin. 2003. The role of phenotypic plasticity in driving genetic evolution. Proceedings of the Royal Society of London B 2003: 1433-1440.

Relyea, R. A. 2003. Predators come and predators go: the reversibility of predator-induced traits. Ecology 84 : 1840-1848.

Smith, G. R. and J. E. Rettig. 1996. Effectiveness of aquatic funnel traps for sampling amphibian larvae. Herpetological Review 27: 190-191.

Zippel, K.C. 1997. Hairy frogs (Trichobatrachus robustus) in the field. Reptiles 5: 68-73. 